Article

\title{
Synthesis of Novel Ethoxylated Quaternary Ammonium Gemini Surfactants for Enhanced Oil Recovery Application
}

\author{
S. M. Shakil Hussain ${ }^{1}$, Muhammad Shahzad Kamal ${ }^{1, *(\mathbb{D})}$ and Mobeen Murtaza ${ }^{2}$ \\ 1 Center for Integrative Petroleum Research, King Fahd University of Petroleum \& Minerals, Dhahran 31261, \\ Saudi Arabia; smshakil@kfupm.edu.sa \\ 2 College of Petroleum Engineering, King Fahd University of Petroleum \& Minerals, Dhahran 31261, \\ Saudi Arabia; Mobeen@kfupm.edu.sa \\ * Correspondence: shahzadmalik@kfupm.edu.sa; Tel.: +966-13-860-8513
}

Received: 31 March 2019; Accepted: 30 April 2019; Published: 8 May 2019

\begin{abstract}
Two aspects are always considered in the design and development of new surfactants for oilfield application. One of them is that surfactant must be sufficiently stable at reservoir temperature and the other is the solubility of the surfactant in the injection water (usually seawater) and the formation brine. Most industrially applied surfactants undergo hydrolysis at elevated temperature and the presence of reservoir ions causes surfactant precipitation. In relevance to this, a novel series of quaternary ammonium gemini surfactants with different length of spacer group (C8, C10, and C12) was synthesized and characterized using FT-IR, ${ }^{13} \mathrm{C}$ NMR, ${ }^{1} \mathrm{H}$ NMR, and MALDI-TOF MS. The gemini surfactants were prepared by solvent-free amidation of glycolic acid ethoxylate lauryl ether with 3-(dimethylamino)-1-propylamine followed by reaction with dibromoalkane to obtain quaternary ammonium gemini surfactants. The gemini surfactants were examined by means of surface properties and thermal stabilities. The synthesized gemini surfactants showed excellent solubility in the formation brine, seawater, and deionized water without any precipitation for up to three months at $90^{\circ} \mathrm{C}$. Thermal gravimetric data revealed that all the gemini surfactants were decomposed above $227^{\circ} \mathrm{C}$, which is higher than the oilfield temperature $\left(\geq 90^{\circ} \mathrm{C}\right)$. The decrease in critical micelle concentration (CMC) and surface tension at $\mathrm{CMC}\left(\gamma_{\mathrm{cmc}}\right)$ was detected by enhancing spacer length in the order $\mathrm{C} 8>\mathrm{C} 10>\mathrm{C} 12$ which suggested that the larger the spacer, the better the surface properties. Moreover, a further decrease in CMC and $\gamma_{\mathrm{cmc}}$ was noticed by enhancing temperature $\left(30^{\circ} \mathrm{C}>60^{\circ} \mathrm{C}\right)$ and salinity (deionized water $>$ seawater). The current study provides a comprehensive investigation of quaternary ammonium gemini surfactants that can be further extended potentially to use as a suitable material for oilfield application.
\end{abstract}

Keywords: enhanced oil recovery; ammonium; gemini surfactants; aqueous; thermal stability; salt tolerance

\section{Introduction}

In the past decades, gemini cationic surfactants containing ammonium headgroup have been extensively used for multiple oilfield applications, such as anti-corrosion in oilfield wells [1], fracturing fluid [2], micellar slug [3], foam generation [4,5], collecting and dispersing the spilled crude oil [6], reservoir stimulation [7] wettability modification [8], and enhanced oil recovery [9,10]. They possess important physicochemical activities including lower critical micelle concentration (CMC), higher interface/surface properties, good solubility, compatible with carbonate rocks, high thermal stability, and unique aggregation behavior as compared to their monomeric counterpart [5,11-13]. 
Gemini cationic surfactants are a comparatively new class that contains two lipophilic tails and two lipophobic headgroups chemically bonded by the spacer. The length of the surfactant tail in gemini cationic surfactants play a significant role to identify the surface properties. For example, increasing the length of the surfactant tail $(\geq \mathrm{C} 14)$ results in lowering $\mathrm{CMC}$ and increasing surface tension at $\mathrm{CMC}$ $\left(\gamma_{\mathrm{cmc}}\right)[4,14,15]$. However, a further increase in the surfactant tail leads to poor solubility in water [16]. The spacer group is perhaps the most important parameter in determining solution properties of the gemini amphiphiles [17]. The spacer group can be short (C2) [18], long (C16) [19], rigid (double bond or benzene ring) [20], flexible (methylene units) [21], lipophilic (hydrocarbon) [22], or hydrophilic (ether linkage) [23]. The length of the spacer significantly affects the size, shape, and morphology of the micelle, that eventually determine their physicochemical properties [17]. The larger length of the spacer results in better surface properties and reduces adsorption of the molecule on to the reservoir rocks [24].

Gemini surfactants can be classified as anionic, cationic, nonionic, and zwitterionic surfactants. The thermal stability and salt tolerance of gemini surfactants are the major challenges as they can precipitate in harsh reservoir conditions. Pal et al. examined the effect of the different spacers on the thermal stability of the nonionic bis (monoglyceride-1-hydrocyl-2-fattyacidester)- $\alpha$ - $\omega$-alkanediether gemini surfactants using thermogravimetric analysis (TGA) and concluded that the gemini surfactant retains their structural integrity up to $448 \mathrm{~K}$. However, precipitation was observed at higher $\mathrm{NaCl}$ concentration [25]. Nonionic and anionic surfactants can have high retention on the carbonate rock surface. Therefore, cationic gemini surfactant can be an attractive choice for carbonate reservoirs owing to low retention of carbonate rocks. Cationic gemini surfactants are not well studied for enhanced oil recovery applications. There are only a few reports in the literature describing the thermal stability and salt tolerance of gemini cationic surfactants containing ammonium headgroup for EOR application [26]. Recently, Wang et al. reported the synthesis of 1,3-2(lauramide propyl dimethyl ammonium chloride) isopropyl alcohol (gemini surfactant) for potential surfactant flooding material and observed a reduction in IFT value $(<0.01 \mathrm{mN} / \mathrm{m})$ upon addition of electrolytes [5]. However, thermal stability and salt tolerance were not studied. Mao et al. revealed the heat resistance and micelle aggregation properties of the viscoelastic (VES) gemini surfactant for oilfield application [2]. Panda and co-workers found enhancement of aqueous solubility of polycyclic aromatic hydrocarbons (PAHs) upon addition of biodegradable ester-linked dicationic geminis of different chain lengths (m-E2-m; $\mathrm{m}=12,14,16$ ) [27]. The solubility and thermal stability of the gemini cationic surfactants in seawater (SW), which is normally the injected water, and in reservoir brine (FW) remains a big challenge. In our previous work, we observed that the gemini surfactants containing ammonium headgroup were only stable in deionized water and showed precipitation in SW and FW [28]. In this work, we achieved excellent solubility and stability of the gemini cationic surfactants with ammonium headgroup in SW and FW by incorporating a proper number of ethoxy (EO) units between the hydrophobic tail and hydrophilic head group.

In this article, three new quaternary ammonium gemini surfactants (GS8, GS10, and GS12) having flexible larger spacer C8, C10, and C12, respectively, were synthesized and characterized with the aid of NMR, (carbon and proton), FT-IR, and MALDI-TOF MS. Special attention was paid to identify the effect of length of spacer on the surface and thermal properties of the synthesized GSs. The surfactant samples were dissolved in FW, SW, and DW, and kept in an oven for three months at $90{ }^{\circ} \mathrm{C}$. The thermal stability of GSs was determined by thermal gravimetric analysis (TGA). Surface properties, such as $C M C$, surface tension at $C M C\left(\gamma_{\mathrm{cmc}}\right)$, maximum surface access $\left(\Gamma_{\max }\right)$, occupied surface area at the interface of air-water $\left(\mathrm{A}_{\min }\right)$ were measured at different conditions of salinity and temperature. This study mainly focuses on synthesis, characterization, thermal stability, salt tolerance, and surface properties of this novel class of surfactants. 


\section{Materials and Methods}

\subsection{Materials}

Glycolic acid ethoxylate lauryl ether (average $\left.\mathrm{M}_{\mathrm{n}} \sim 690\right), \mathrm{NaF}(\geq 99 \%)$, 3-(dimethylamino)-1-propylamine (99\%), 1,8-dibromooctane (98\%), 1,10-dibromodecane (97\%), 1,12-dibromododecane (98\%), aluminum oxide (99.99\%), were acquired from Aldrich company. The salts, such as $\mathrm{CaCl}_{2}, \mathrm{Na}_{2} \mathrm{SO}_{4}, \mathrm{MgCl}_{2}, \mathrm{NaHCO}_{3}, \mathrm{NaCl}$, were used for the preparation of FW and SW. The concentration of each salt is given in Table 1 and all these salts were purchased from Panreac.

\subsection{Elucidation of Chemical Structure}

The structure characterization tools including NMR (carbon and proton), FT-IR, MALDI-TOF MS were used to confirm the chemical structure of all the synthesized gemini surfactants (GS8, GS10, and GS12). ${ }^{13} \mathrm{C}$ and ${ }^{1} \mathrm{H} / \mathrm{NMR}$ spectra were recorded on a Jeol 1500 spectrometer (Jeol, Tokyo, Japan). The FT-IR data was recorded on a 16F Perkin-Elmer FT-IR spectrometer (Perkin-Elmer, Waltham, MA, USA). MALDI-TOF MS spectra of the GSs were recorded on a Bruker SolariX XR instrument (Bruker, Billerica, MA, USA) in a matrix of Dithranol in dichloromethane.

\subsection{Solubility Experiments}

The gemini amphiphiles (GS8, GS10, GS12) (10 wt \% each) were dissolved in FW, SW, DW, and kept in an oven for three months. The temperature of the oven was set at $90{ }^{\circ} \mathrm{C}$ and the solubility was visually observed with elapsed time.

\subsection{Thermal Gravimetric Analysis}

SDT Q600 machine from TA instrument was used for the TGA measurement (New Castle, $\mathrm{DE}, \mathrm{USA})$. The experiment was done with a fixed heating rate $\left(20^{\circ} \mathrm{C} / \mathrm{min}\right)$ and fixed nitrogen flow $(100 \mathrm{~mL} / \mathrm{min})$, and the temperature interval was $30^{\circ} \mathrm{C}$ to $500{ }^{\circ} \mathrm{C}$.

\subsection{Surface Tension Experiments}

Surface tension values for GS8, GS10, and GS12 were investigated with the aid of a force tensiometer (Sigma 702, Biolin Scientific, Gothenburg, Sweden) using the Wilhelmy plate technique. The experiments were conducted at $30 \pm 0.1^{\circ} \mathrm{C}$ and $60 \pm 0.1^{\circ} \mathrm{C}$. Wilhelmy plate was washed using DW and burnt on a blue flame before every experiment. The surface tension of DW was examined as a benchmark.

\subsection{Synthesis}

\section{Synthesis of GS8}

The GS8 was synthesized as depicted in Scheme 1. Glycolic acid ethoxylate lauryl ether (6) (average $\mathrm{Mn} \sim 690)(10 \mathrm{~g}, 14.49 \mathrm{mmol}$ ) and 3-(dimethylamino)-1-propylamine (5) (2.96 g, $28.99 \mathrm{mmol})$ were refluxed for $6 \mathrm{~h}$ at $160{ }^{\circ} \mathrm{C}$ in a $250 \mathrm{~mL}$ round bottom flask using sodium fluoride $(0.06 \mathrm{~g}, 1.45 \mathrm{mmol})$ as a catalyst [29]. An extra 3-(dimethylamino)-1-propylamine (2.22 g, $21.74 \mathrm{mmol}$ ) was introduced in order to convert all the glycolic acid into amide intermediate (4) and the reaction progressed an extra four hours. Eventually, the unreacted 3-(dimethylamino)-1-propylamine was extracted and the solid sodium fluoride was removed to acquire intermediate 4 . In the second step, intermediate 4 (10.0 g, $12.92 \mathrm{mmol})$ was refluxed with 1,8-dibromooctane $(1.41 \mathrm{~g}, 5.17 \mathrm{mmol})$ in anhydrous ethanol $(5 \mathrm{~mL})$ for $48 \mathrm{~h}$ at $80^{\circ} \mathrm{C}$. Finally, the crude material was refined by column chromatography with ethanol (mobile phase) to acquired GS8 as a thick oil [30].

GS10 and GS12 were synthesized in the exact same manner as GS8. 

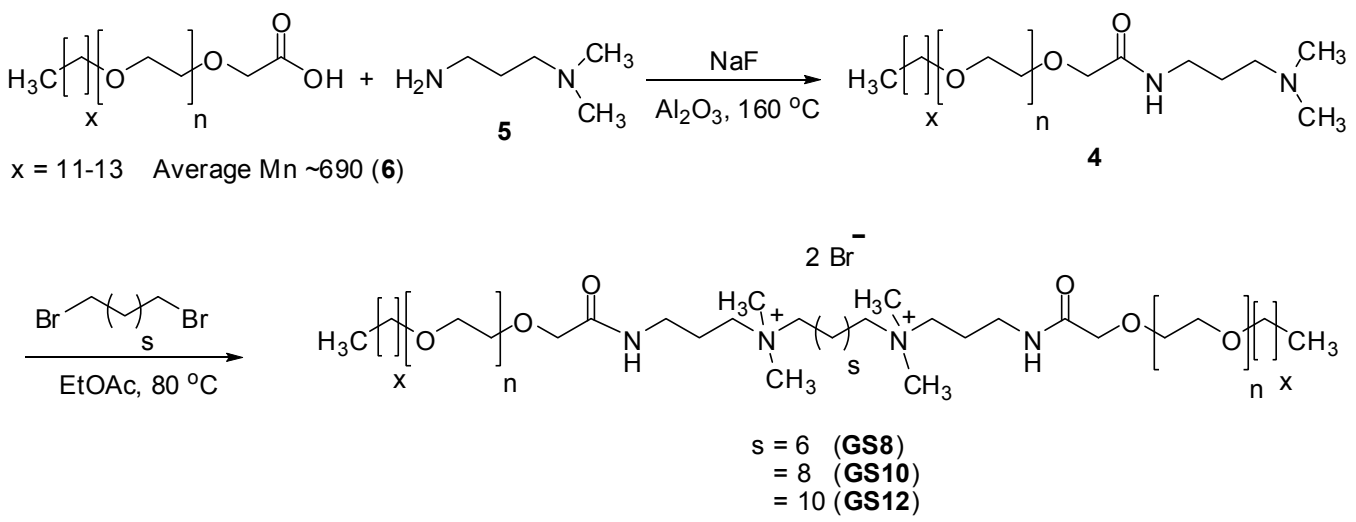

Scheme 1. Synthesis of quaternary ammonium gemini surfactants (GS8, GS10, and GS12).

\section{Results}

Three quaternary ammonium gemini surfactants (GS8, GS10, and GS12) having flexible larger spacer were synthesized by treating glycolic acid ethoxylate lauryl ether (6) with 3-(dimethylamino)-1-propylamine (5) using NaF catalyst to form intermediate (4) (Scheme 1, Figure 1). The intermediate (4) was then further reacted individually with 1,8-dibromooctane, 1,10-dibromodecane, and 1,12-dibromododecane to acquired GS8, GS10, and GS12, respectively.

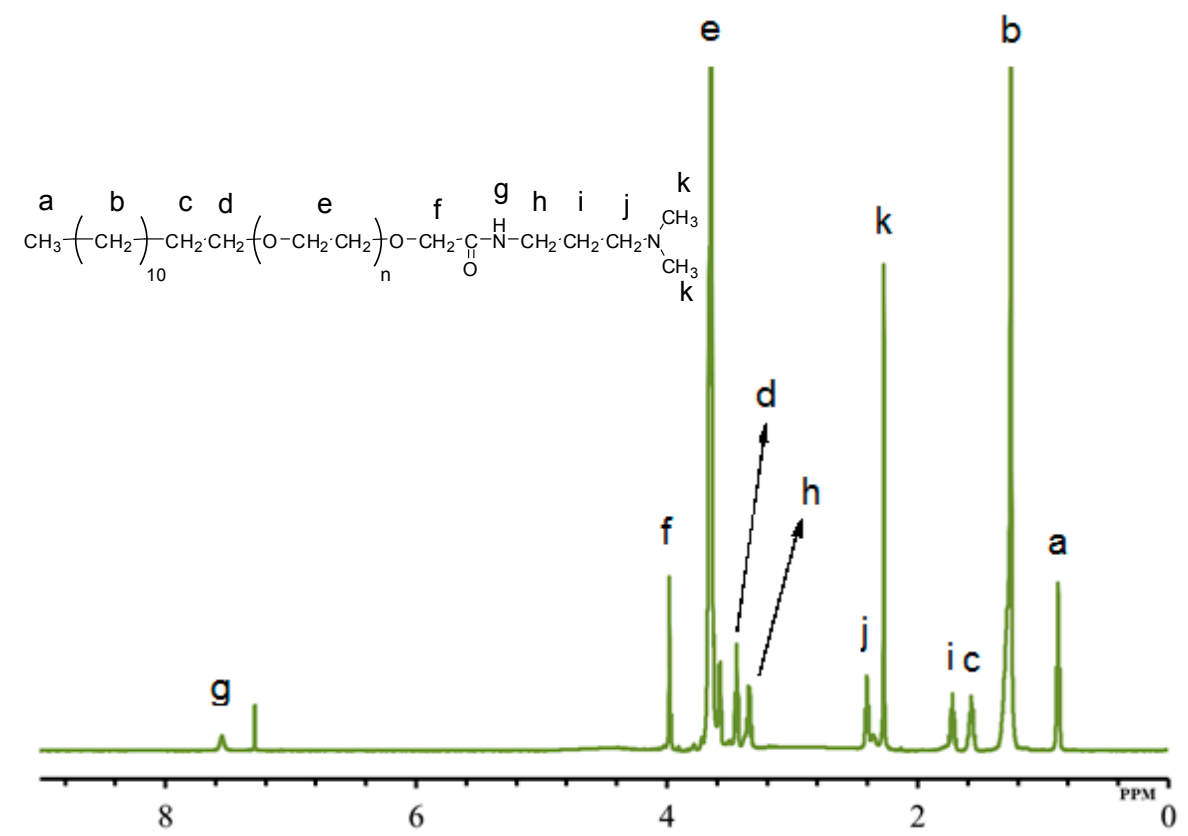

Figure 1. ${ }^{1} \mathrm{H}$ NMR of intermediate 4.

\subsection{Structure Confirmation}

The structure elucidation of all gemini surfactants was done using ${ }^{1} \mathrm{H}$ NMR, ${ }^{13} \mathrm{C}$ NMR, FTIR, and MALDI-TOF MS. The structure elucidation of GS12 is illustrated here, while the data of GS8 and GS10 is given in Supplementary Materials (Figures S1-S8). The ${ }^{1} \mathrm{H}$ NMR spectra of GS12 (Table 1, Figure 2) showed the existence of characteristic signals at $\delta 0.88 \mathrm{ppm}$ and $\delta 1.25 \mathrm{ppm}$ corresponding to the $\mathrm{CH}_{3}$ and $\mathrm{CH}_{2}$ moieties constituting hydrophobic tail. The presence of $\mathrm{CH}_{3}$ groups connected to the quaternary ammonium $\left[-\left(\mathrm{CH}_{3}\right)_{2}-\mathrm{N}-\left(\mathrm{CH}_{2}\right)_{12}-\mathrm{N}-\left(\mathrm{CH}_{3}\right)_{2}-\right]$ was evident from a singlet peak at $\delta 3.27$ ppm [5]. The most intense peak at $\delta 3.65 \mathrm{ppm}$ was attributed to the presence of the ethylene oxide chain $\left(-\mathrm{O}-\mathrm{CH}_{2}-\mathrm{CH}_{2}-\mathrm{O}-\mathrm{CH}_{2}-\mathrm{CH}_{2}-\right)$ [31]. The singlet peak that appeared at $\delta 4.03$ ppm was coupled 
with the $\mathrm{CH}_{2}$ group next to the carbonyl group $\left[-\mathrm{CH}_{2}-\mathrm{CH}_{2}-\mathrm{O}-\mathrm{CH}_{2}-\mathrm{C}=\mathrm{O}-\mathrm{NH}-\right]$. Characteristic signals at $\delta 7.98 \mathrm{ppm}$ could be coupled to the proton of the amide group [ $\left.-\mathrm{CH}_{2}-\mathrm{C}=\mathrm{O}-\mathrm{NH}-\mathrm{CH}_{2}-\right]$ [32].

Table 1. ${ }^{1} \mathrm{H}$ NMR data exhibiting description of proton-type in GS12 [33-37].

\begin{tabular}{|c|c|c|c|c|c|c|c|c|c|c|c|}
\hline \multirow{3}{*}{$\begin{array}{c}\text { Gemini } \\
\text { Surfactants }\end{array}$} & \multicolumn{11}{|c|}{${ }^{1} \mathrm{H}$ NMR ( $\delta$ in ppm, $\mathrm{CDCl}_{3}$ Solvent at $500 \mathrm{MHz}$ ) } \\
\hline & \multicolumn{4}{|c|}{ Alkyl Tail } & \multicolumn{2}{|c|}{ Ethoxy Chain } & \multirow{2}{*}{$\begin{array}{c}\text { Amide } \\
\begin{array}{c}\text { NH } \\
\text { (g) }\end{array}\end{array}$} & \multicolumn{2}{|c|}{ Amido-Amine } & \multicolumn{2}{|c|}{ Spacer Group } \\
\hline & $\begin{array}{l}\mathrm{CH}_{3} \\
\text { (a) }\end{array}$ & $\begin{array}{l}\mathrm{CH}_{2} \\
(\mathrm{~b}, \mathrm{o})\end{array}$ & $\begin{array}{c}\mathrm{CH}_{2} \\
\text { (c) }\end{array}$ & $\begin{array}{l}\mathrm{CH}_{2} \\
(\mathrm{~d} \mathrm{j} \mathrm{l})\end{array}$ & $\begin{array}{c}\left(\mathrm{CH}_{2}\right)_{2} \\
(\mathrm{e})\end{array}$ & $\begin{array}{l}\mathrm{CH}_{2} \\
\text { (f) }\end{array}$ & & $\begin{array}{l}\mathrm{CH}_{2}(\mathbf{h}) \\
\mathrm{CH}_{3}(\mathrm{k})\end{array}$ & $\begin{array}{l}\mathrm{CH}_{2} \\
\text { (i) }\end{array}$ & $\begin{array}{l}\mathrm{CH}_{2} \\
(\mathrm{~m})\end{array}$ & $\begin{array}{c}\mathrm{CH}_{2} \\
\text { (n) }\end{array}$ \\
\hline GS8 & 0.88 & 1.26 & 1.57 & 3.44 & 3.64 & 4.03 & 7.96 & 3.25 & 1.75 & 2.06 & 1.44 \\
\hline GS10 & 0.88 & 1.26 & 1.57 & 3.44 & 3.65 & 4.03 & 7.97 & 3.27 & 1.76 & 2.06 & 1.40 \\
\hline GS12 & 0.88 & 1.26 & 1.57 & 3.44 & 3.65 & 4.03 & 7.98 & 3.27 & 1.74 & 2.07 & 1.37 \\
\hline
\end{tabular}

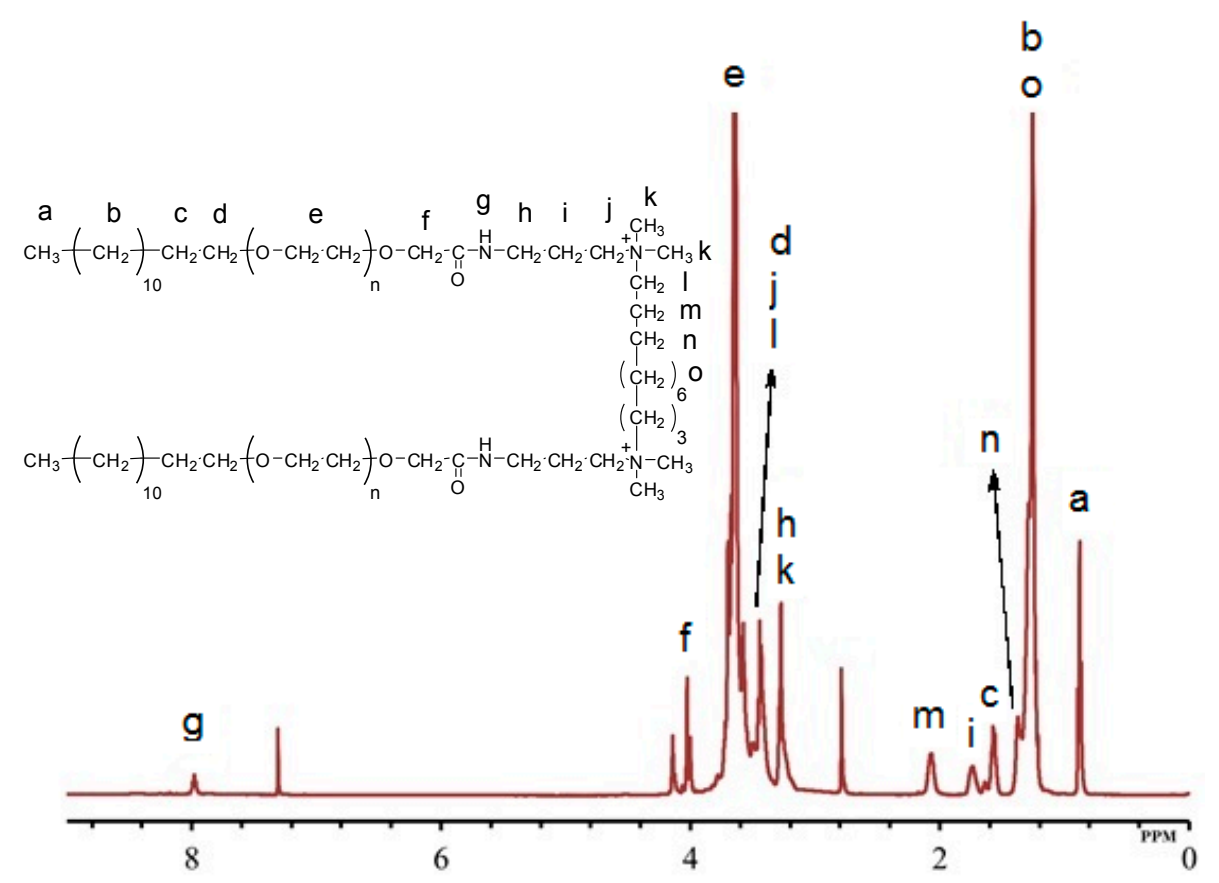

Figure 2. ${ }^{1} \mathrm{H}$ NMR of quaternary ammonium gemini surfactants (GS12).

The ${ }^{13} \mathrm{C}$ NMR spectra of GS12 (Table 2, Figure 3) displayed the signals at $\delta 14.0 \mathrm{ppm}$ and $\delta 22.5-31.8$ ppm related to the $\mathrm{CH}_{3}$ and $\mathrm{CH}_{2}$ groups constituting hydrophobic tail. The existence of $\mathrm{CH}_{3}$ groups joined to the quaternary ammonium $\left[-\left(\mathrm{CH}_{3}\right)_{2}-\mathrm{N}-\left(\mathrm{CH}_{2}\right)_{12}-\mathrm{N}-\left(\mathrm{CH}_{3}\right)_{2}-\right]$ was marked from signals at $\delta$ $51.1 \mathrm{ppm}$. In addition, characteristic signals at $\delta 62.1 \mathrm{ppm}$ and $\delta 64.5 \mathrm{ppm}$ correspond to the two $\mathrm{CH}_{2}$ groups at the quaternary ammonium $\left[-\mathrm{CH}_{2}-\mathrm{N}-\left(\mathrm{CH}_{3}\right)_{2}-\mathrm{CH}_{2}-\left(\mathrm{CH}_{2}\right)_{10}-\mathrm{CH}_{2}-\left(\mathrm{CH}_{3}\right)_{2}-\mathrm{N}-\mathrm{CH}_{2}-\right]$ [38]. The most intense peak at $\delta 70.4 \mathrm{ppm}$ was attributed to the presence of the ethylene oxide chain $\left(-\mathrm{O}-\mathrm{CH}_{2}-\mathrm{CH}_{2}-\mathrm{O}-\mathrm{CH}_{2}-\mathrm{CH}_{2}-\right.$ ) [31]. Characteristic signals at $\delta 170.8 \mathrm{ppm}$ could be attributed to the carbon of the amide group $\left[-\mathrm{CH}_{2}-\mathrm{C}=\mathrm{O}-\mathrm{NH}-\mathrm{CH}_{2}-\right]$.

Table 2. ${ }^{13} \mathrm{C}$ NMR data describing the chemical shift values in GS12.

\begin{tabular}{cc}
\hline Gemini Surfactants & ${ }^{13} \mathbf{C}$ NMR $\left(\delta\right.$ in ppm, $\mathbf{C D C l}_{3}$ Solvent at $\left.\mathbf{1 2 5} \mathbf{M H z}\right)$ \\
\hline GS8 & $14.0,22.6,25.9,29.2,29.4,29.5,31.8,35.7,51.1,62.1,64.6,70.4,170.9$ \\
GS10 & $13.9,22.5,25.9,29.2,29.3,29.5,31.7,35.7,51.0,62.0,64.4,70.3,170.9$ \\
GS12 & $14.0,22.5,26.0,29.2,29.3,29.4,31.8,35.6,51.1,62.1,64.5,70.4,170.8$ \\
\hline
\end{tabular}




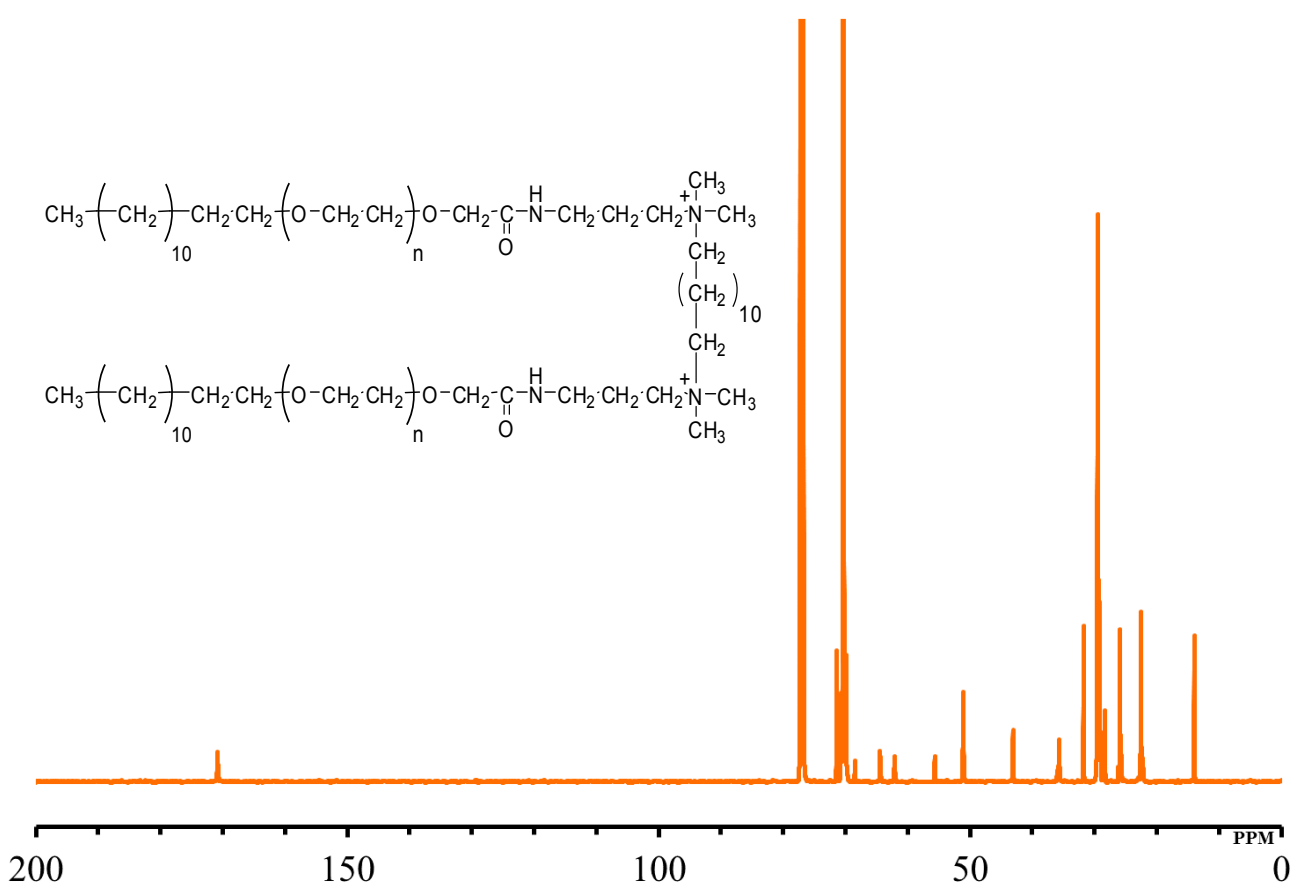

Figure $3 .{ }^{13} \mathrm{C}$ NMR of quaternary ammonium gemini surfactants (GS12).

The FT-IR data of GS12 (Table 3, Figure 4) revealed an adsorption band at $3412 \mathrm{~cm}^{-1}$ correspond to $\mathrm{N}-\mathrm{H}$ stretching vibration. The signals at $2855 \mathrm{~cm}^{-1}$ and $2921 \mathrm{~cm}^{-1}$ can be attributed to the symmetric and asymmetric vibration of the $\mathrm{CH}_{2}$ groups. Characteristic signals at $1627 \mathrm{~cm}^{-1}$ and $1542 \mathrm{~cm}^{-1}$ could be coupled with the $\mathrm{C}=\mathrm{O}$ stretch of amide I and amide II band [38]. Resonance signals at $1463 \mathrm{~cm}^{-1}$ and $1347 \mathrm{~cm}^{-1}$ is a result of $\mathrm{CH}_{2}$ and $\mathrm{CH}_{3}$ bending vibrations, respectively. The most intense peak at $1096 \mathrm{~cm}^{-1}$ corresponds to the ether (C-O-C) functional group [39].

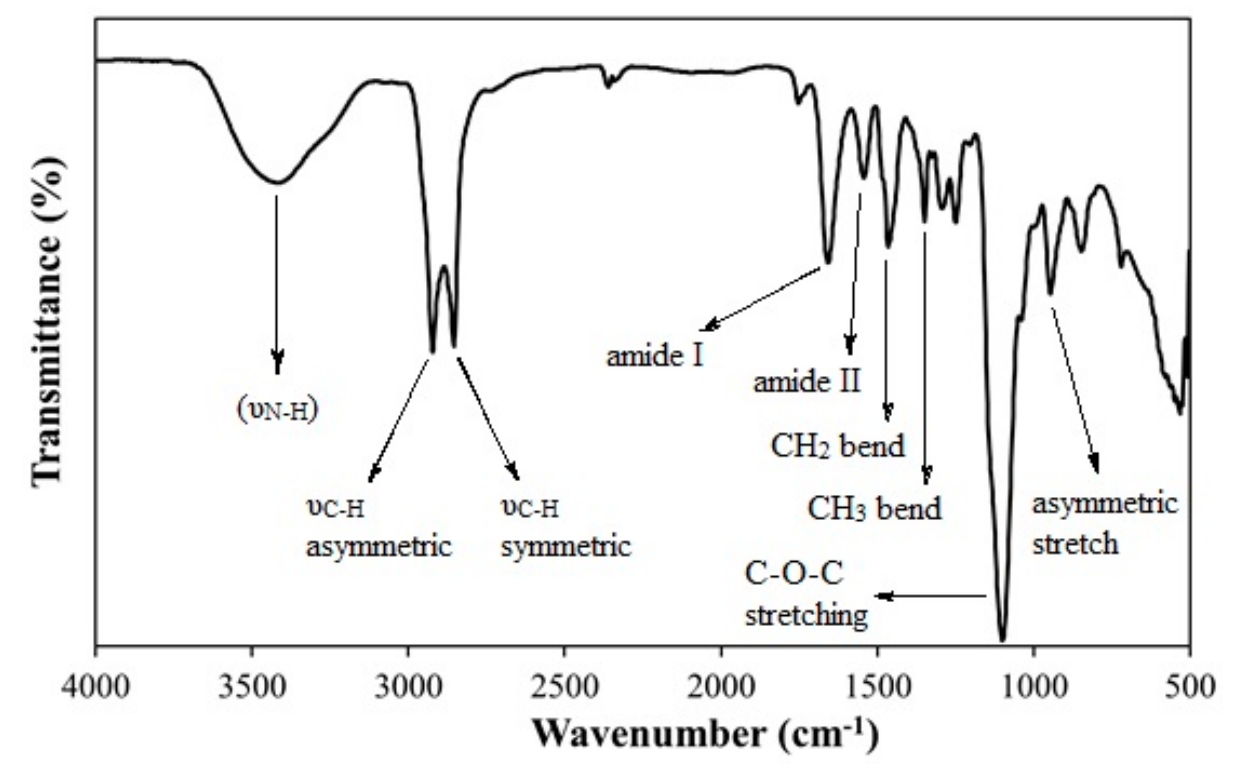

Figure 4. FT-IR spectra of quaternary ammonium gemini surfactants (GS12). 
Table 3. FT-IR spectral data of the quaternary ammonium gemini surfactants (GS12).

\begin{tabular}{|c|c|c|c|c|c|c|c|c|c|}
\hline \multirow{2}{*}{$\begin{array}{c}\text { Gemini } \\
\text { Surfactants }\end{array}$} & \multicolumn{9}{|c|}{ FTIR Adsorption Bands $\left(v\right.$ in $\left.\mathrm{cm}^{-1}\right)$} \\
\hline & $\left(v_{N-H}\right)$ & $\begin{array}{l}v_{\mathrm{C}-\mathrm{H}} \\
\text { asym. }\end{array}$ & $\begin{array}{l}v_{\mathrm{C}-\mathrm{H}} \\
\text { sym. }\end{array}$ & $\begin{array}{l}\text { Amide } \\
\text { (I) }\end{array}$ & $\begin{array}{l}\text { Amide } \\
\text { (II) }\end{array}$ & $\begin{array}{c}\mathrm{CH}_{2} \\
\text { (Bend) }\end{array}$ & $\begin{array}{c}\mathrm{CH}_{3} \\
\text { (Bend) }\end{array}$ & $\begin{array}{l}\text { C-O-C } \\
\text { Stretch }\end{array}$ & $\begin{array}{l}\text { asym. } \\
\text { Stretch }\end{array}$ \\
\hline GS8 & 3409 & 2920 & 2853 & 1628 & 1545 & 1464 & 1348 & 1097 & 945 \\
\hline GS10 & 3411 & 2922 & 2851 & 1631 & 1544 & 1465 & 1350 & 1099 & 947 \\
\hline GS12 & 3412 & 2921 & 2855 & 1627 & 1542 & 1463 & 1347 & 1096 & 946 \\
\hline
\end{tabular}

According to MALDI-TOF MS spectra (Table 4, Figure 5), the characteristic peak at 724.5 may be attributed to the homolytic bond breaking between quaternary ammonium and terminal carbon of spacer. Such kind of homolytic cleavage gives rise to the radical cation and demonstrates that the GS12 containing $\mathrm{n}=11$ and $\mathrm{x}=9$ is the major component.

Table 4. MALDI-TOF MS analysis of quaternary ammonium gemini surfactants (GS8, GS10, and GS12).

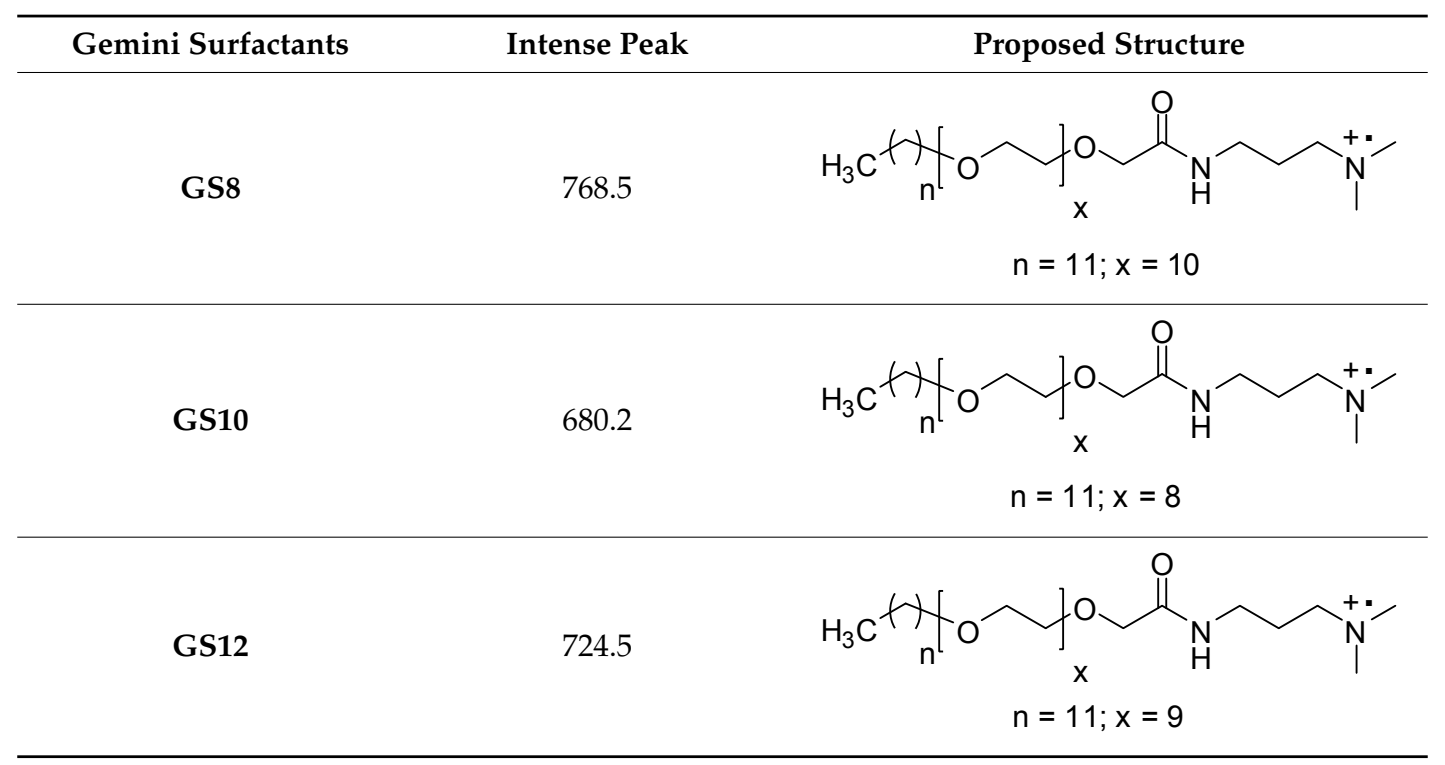

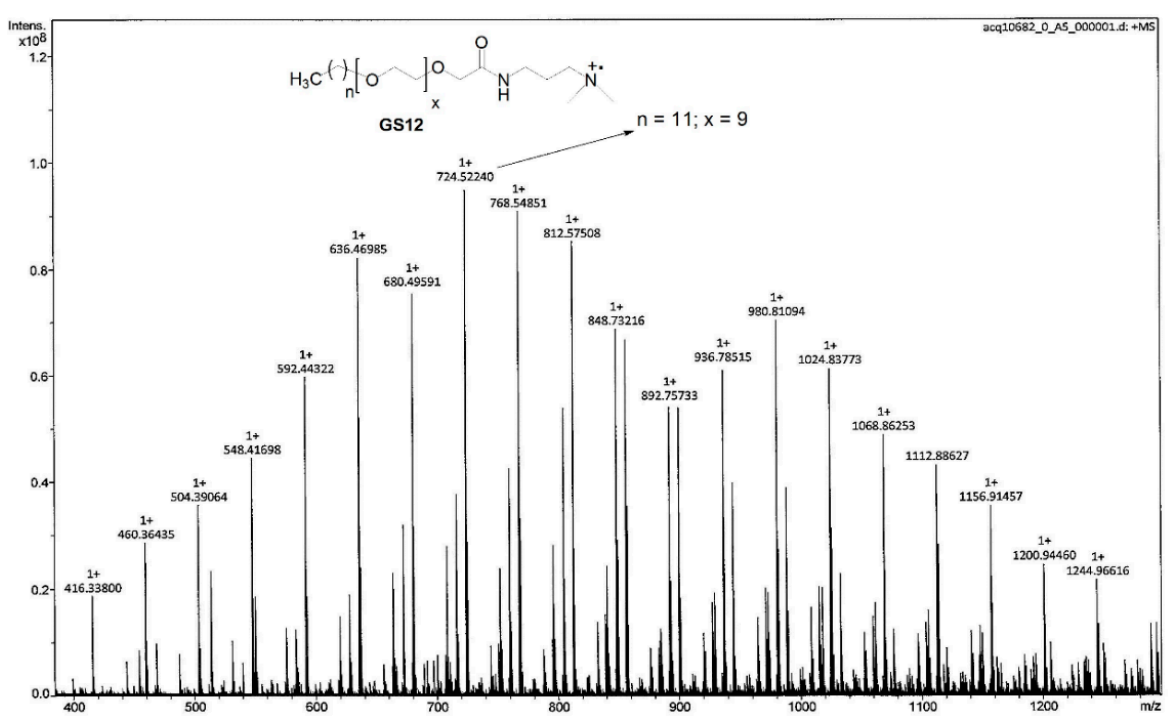

Figure 5. MALDI-TOF MS of quaternary ammonium gemini surfactants (GS12). 


\subsection{Heat Stability}

\subsubsection{Short-Term Heat Stability}

Stability of surfactant in a hot environment is the key factor for its oilfield application [40-42]. We examined the heat stability of the three-quaternary ammonium gemini surfactants (GS8, GS10, and GS12) at elevated temperature with the help of TGA. All three GSs exhibited almost similar thermal behavior (Figure 6) and thermal decomposition was observed at two stages. The initial 3.3\% loss in weight for all GSs may be associated with the loss of solvent impurities and residual water. A second and sharp loss in weight for all GSs was identified at $227^{\circ} \mathrm{C}$ reflecting the degrading effect of temperature on the chemical structure of GS8, GS10, and GS12 and it was significantly higher than the real oilfield temperature $\left(\geq 90^{\circ} \mathrm{C}\right)$. GS8, GS10, and GS12 contain the same number of hydrophobic units (tail groups) and hydrophilic units (EO groups), and the same ammonium headgroups. They differ with each other by two methylene units in the spacer group. Therefore, a significant difference in thermal properties was not observed. In summary, the variation of spacer length has no significant effect on the thermal stability of the GSs and, overall, GSs were found to be thermally stable at elevated temperature.

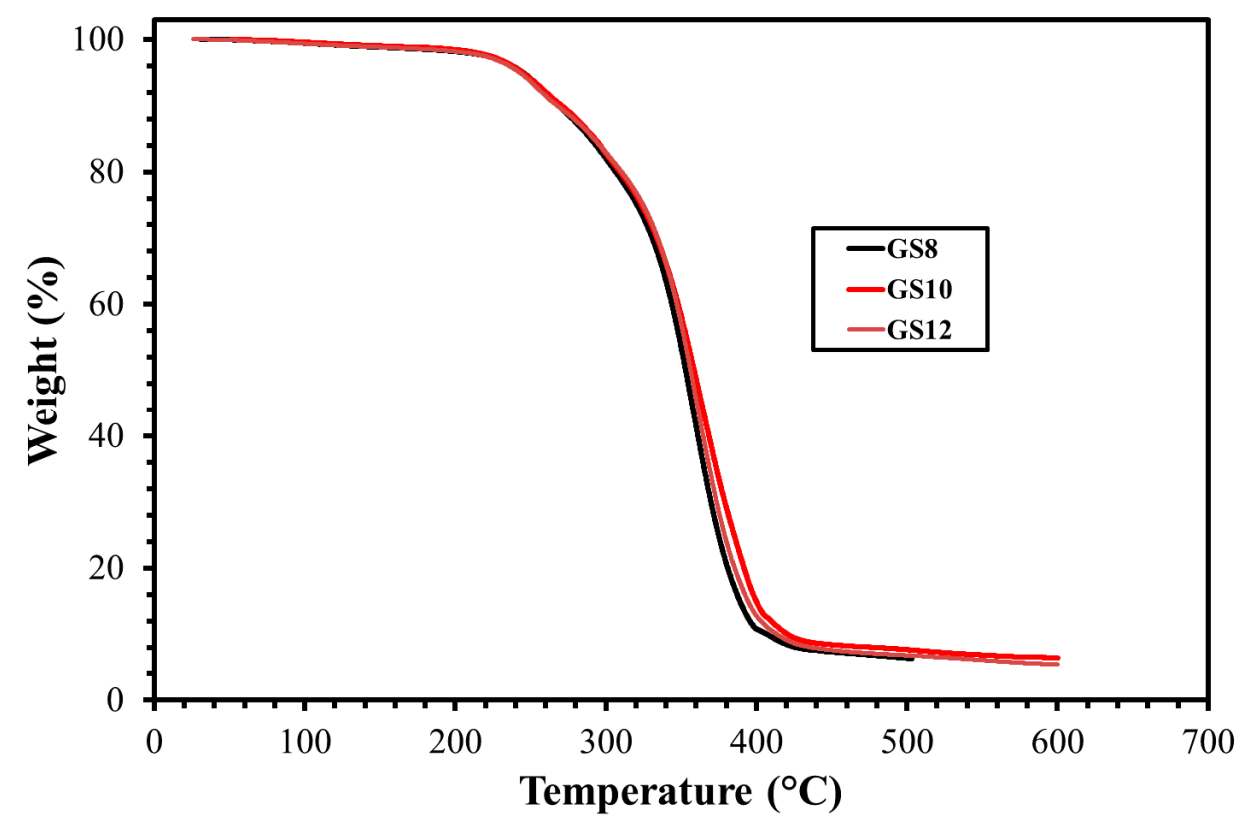

Figure 6. Thermal gravimetric analysis of gemini surfactants with different spacer length.

\subsubsection{Long-Term Heat Stability}

Long-term thermal stability is the pre-requisite for the material subjected to oilfield application. The applied surfactants stay in the oilfield for a long time and the high temperature of the oilfield $\left(\geq 90^{\circ} \mathrm{C}\right)$ can lead to surfactant decomposition. We investigated long-period heat stability of the synthesized GS10 by the aging procedure in which GS10 was dissolved in seawater and left in an oven over a period of three months at $90^{\circ} \mathrm{C}$ followed by structure elucidation of the aged GS10 sample with the aid of NMR and FT-IR spectroscopy. As revealed by the ${ }^{1} \mathrm{H}$ NMR spectra of the aged sample of GS (Figure 7), the terminal $\mathrm{CH}_{3}$ of the lipophilic tail appeared at $\delta=0.88 \mathrm{ppm}$. The multiple $\mathrm{CH}_{2}$ groups in the lipophilic tail were observed at $\delta=1.26 \mathrm{ppm}$. The multiple $\mathrm{CH}_{3}$ groups at the ammonium headgroup were resonated at $\delta=3.29 \mathrm{ppm}$. The $\mathrm{CH}_{2}$ groups in the ethoxy chain were detected $\delta=$ $3.65 \mathrm{ppm}$. The singlet peak of amide proton was identified at $\delta=7.97 \mathrm{ppm}$. As displayed in the ${ }^{13} \mathrm{C}$ NMR spectra of the aged sample of GS10 (Figure 8), the terminal $\mathrm{CH}_{3}$ of the lipophilic tail was observed at $\delta=13.9 \mathrm{ppm}$. The multiple $\mathrm{CH}_{2}$ groups in the lipophilic tail were detected at $\delta=22.5-31.8 \mathrm{ppm}$. The multiple $\mathrm{CH}_{3}$ groups at the ammonium headgroup were identified at $\delta=51.1 \mathrm{ppm}$. Similarly, the $\mathrm{CH}_{2}$ groups from both sides of ammonium headgroup were resonated at $\delta=62.0 \mathrm{ppm}$ and $\delta=64.4 \mathrm{ppm}$. 
The multiple $\mathrm{CH}_{2}$ groups in the ethoxy chain were seen by the signals at $\delta=69.9 \mathrm{ppm}$. The signals at $\delta=170.9 \mathrm{ppm}$ can be attributed to the carbonyl carbon of the amide group. The FT-IR spectra of GS10 (Figure 9) exhibited an adsorption band at $3414 \mathrm{~cm}^{-1}$ related to N-H stretching. Two sharp peaks at $2853 \mathrm{~cm}^{-1}$ and $2919 \mathrm{~cm}^{-1}$ can be related to the symmetric and asymmetric stretching of the $\mathrm{CH}_{2}$ groups. Characteristic peaks at $1625 \mathrm{~cm}^{-1}$ and $15,439 \mathrm{~cm}^{-1}$ may be attributed to the carbonyl stretching of amide I and amide II band. The signals at $1461 \mathrm{~cm}^{-1}$ and $1344 \mathrm{~cm}^{-1}$ can be coupled with the $\mathrm{CH}_{2}$ and $\mathrm{CH}_{3}$ bending, respectively. The intense peak at $1097 \mathrm{~cm}^{-1}$ can be related to the ether $(\mathrm{C}-\mathrm{O}-\mathrm{C})$ group. Overall, the NMR and FT-IR spectra of the GS10 before and after aging were in agreement with the structure and no structure decomposition was observed.

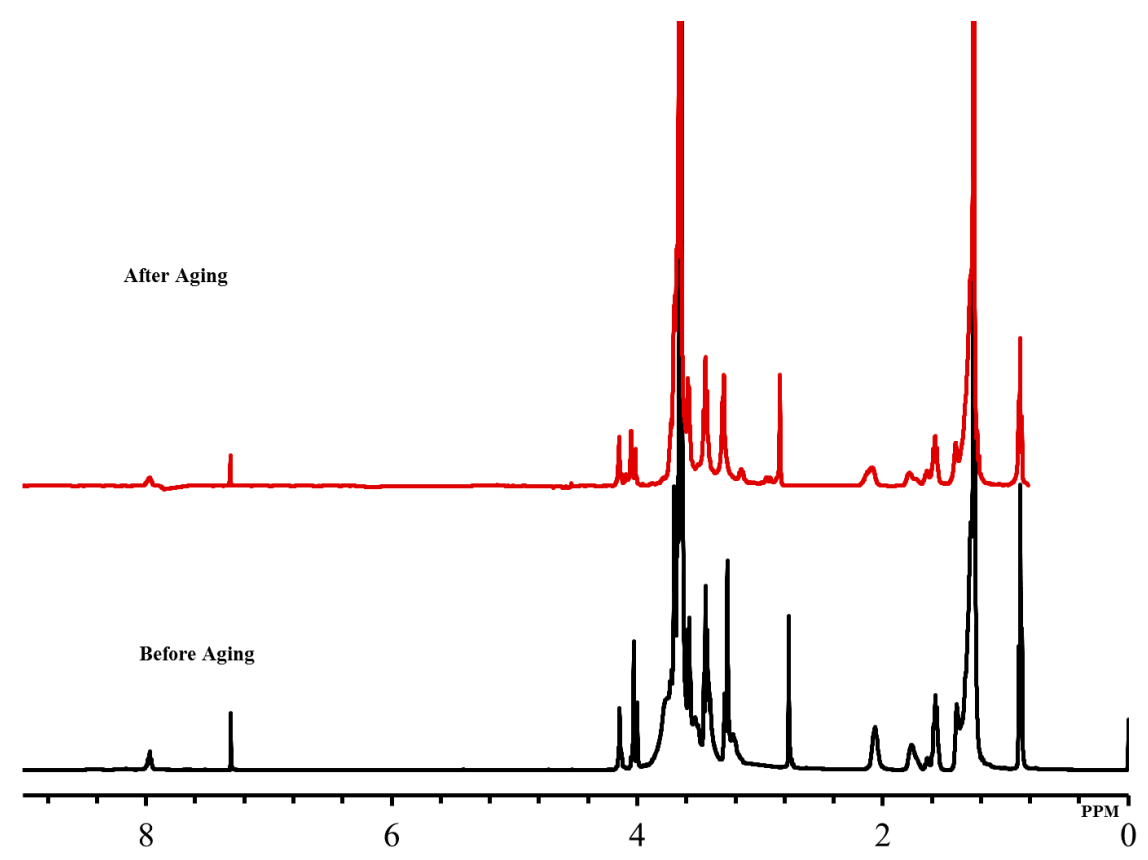

Figure 7. ${ }^{1} \mathrm{H}$ NMR of GS10 sample before aging and after aging.

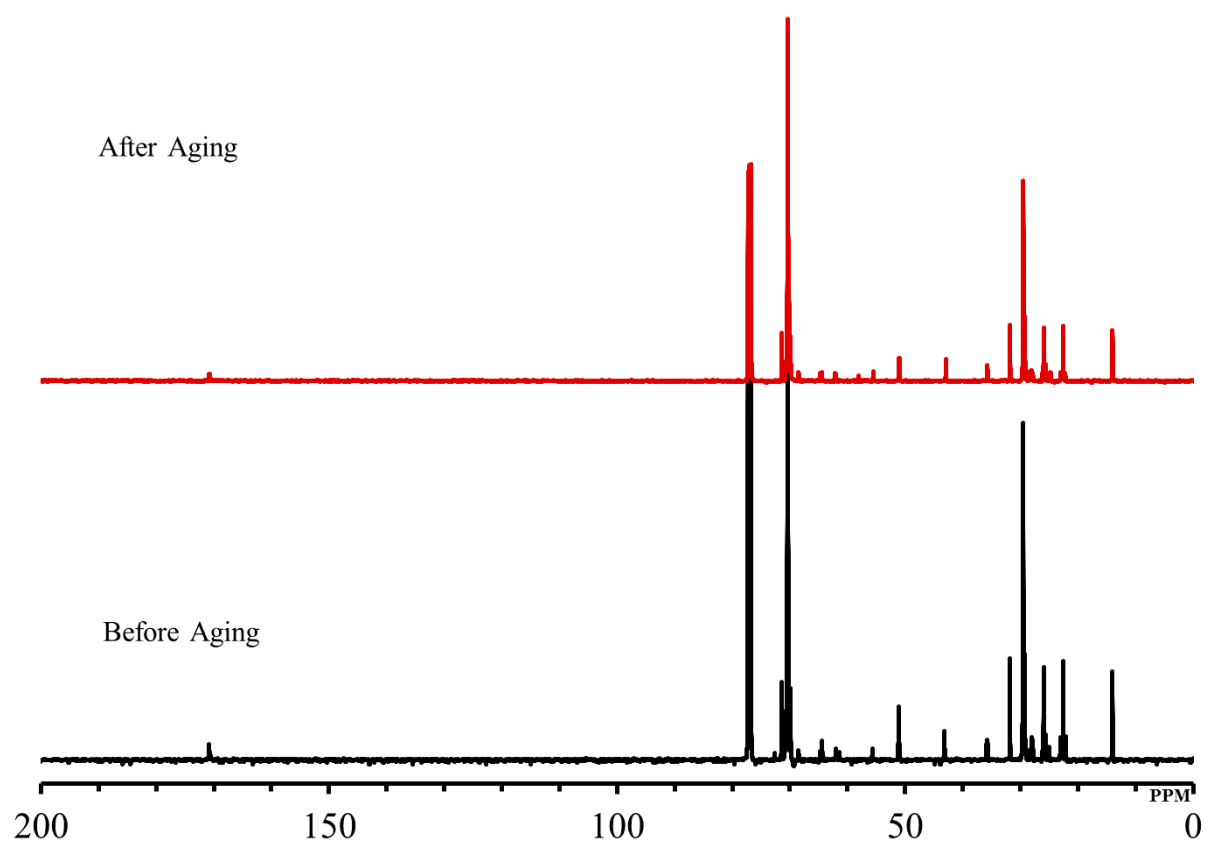

Figure $8 .{ }^{13} \mathrm{C}$ NMR of GS10 sample before aging and after aging. 


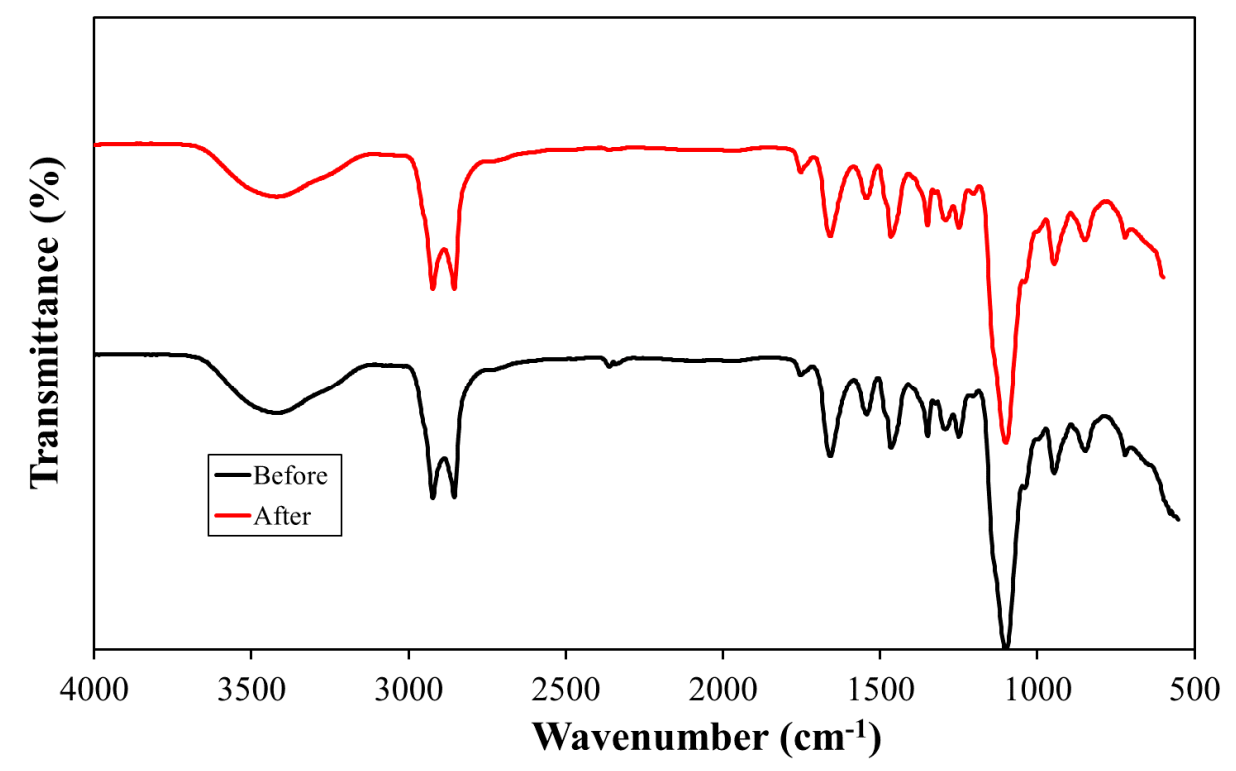

Figure 9. FT-IR spectra of GS10 before aging and after aging.

\subsection{Salt Resistance and Solubility}

Surfactant solubility and stability in the presence of reservoir ions is one of the most important properties of any surfactant selected for oilfield application. The presence of different monovalent and divalent salts in injected water (normally seawater) and FW accelerates the formation of precipitates and diminishes the surfactant ability to reduce IFT and alter rock wettability. It was observed that the addition of a proper number of ethoxy (EO) units between the lipophilic tail and lipophobic headgroup enhances the solubility of the GSs in all kinds of water (DW, SW, and FW). The increase in solubility with the addition of EO units can be explained by the hydrogen bonding effect. The oxygen atom in EO units form hydrogen bonding with the hydrogen atom of water molecules and an increasing number of EO units results in more hydrogen bonding which further enhances the surfactant solubility (Figure 10). The aqueous solubility and salt resistance level of GSs were investigated by dissolving the GSs samples in SW and FW, then they were placed in an oven for up to three months at $90{ }^{\circ} \mathrm{C}$. The percentage of all salts in aqueous surfactant solution is outlined in Table 5. All three surfactants (GS8, GS10, GS12) exhibited pronounced solubility in DW, SW, and FW without precipitation, phase separation, or cloudiness for up to three months at $90^{\circ} \mathrm{C}$ (Figure 11).

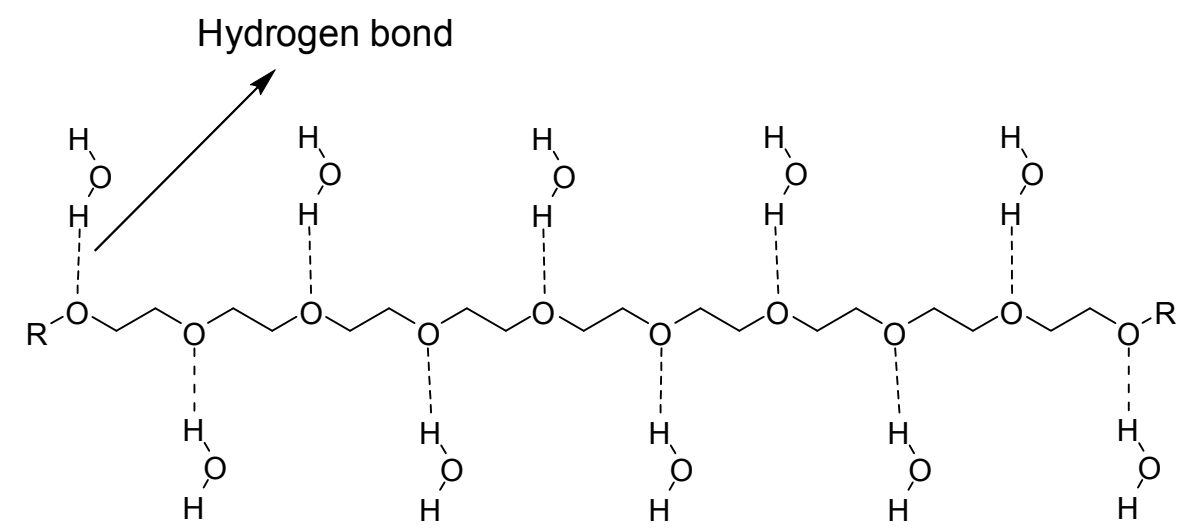

Figure 10. Schematic diagram of hydrogen bonding between ethoxy units and water molecules. 
Table 5. The amount of salts in simulated FW and SW.

\begin{tabular}{ccc}
\hline Ions & FW $(\mathrm{g} / \mathrm{L})$ & SW $(\mathrm{g} / \mathrm{L})$ \\
\hline $\mathrm{Na}^{+}$ & 59.5 & 18.3 \\
$\mathrm{Ca}^{2+}$ & 19.1 & 0.7 \\
$\mathrm{Mg}^{2+}$ & 2.5 & 2.1 \\
$\mathrm{SO}_{4}{ }^{2-}$ & 0.4 & 4.3 \\
$\mathrm{Cl}^{-}$ & 132.1 & 32.2 \\
$\mathrm{HCO}_{3}{ }^{-}$ & 0.4 & 0.1 \\
$\mathrm{Total}^{-}$ & 214 & 57.7 \\
\hline
\end{tabular}

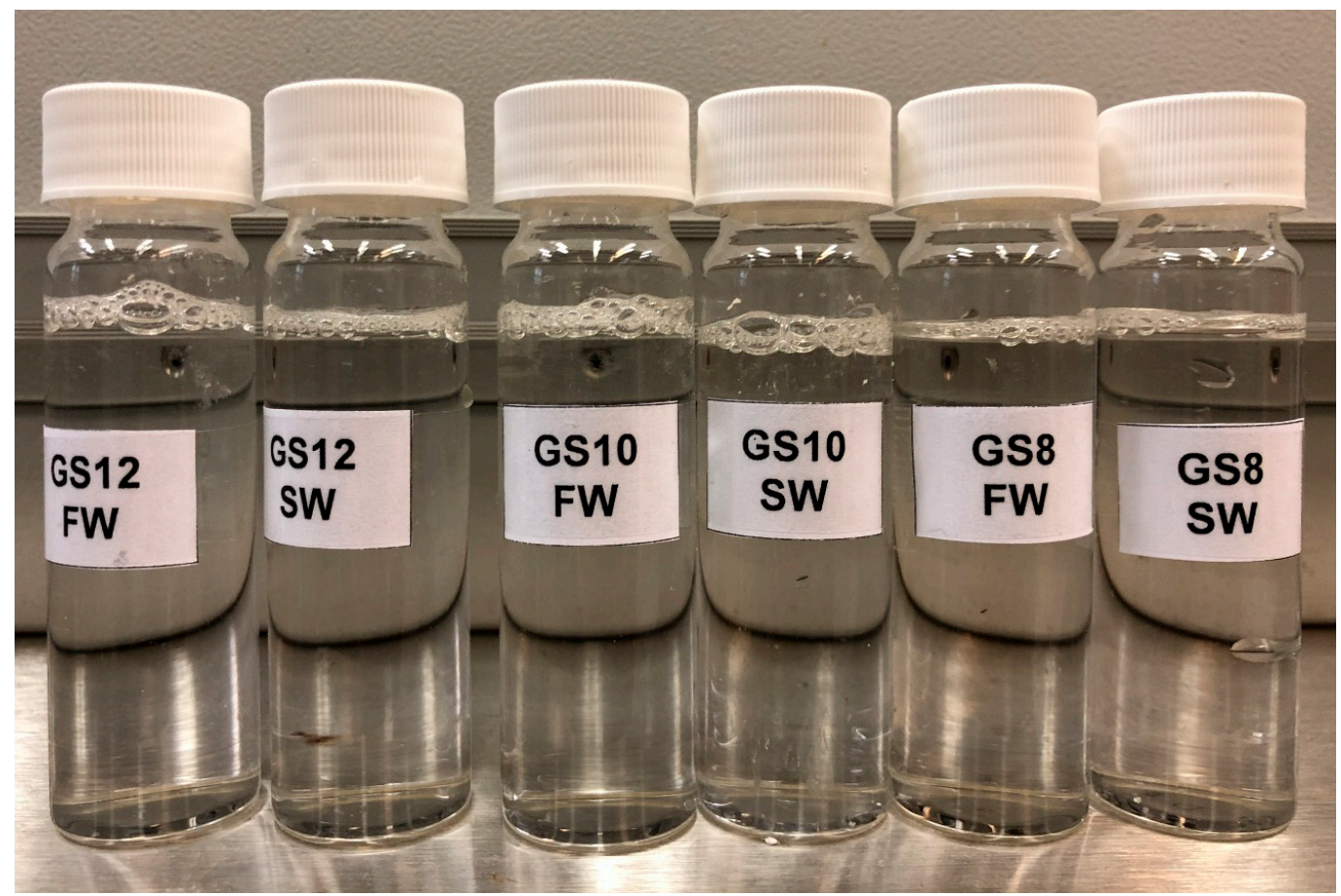

Figure 11. Snapshot of GS8, GS10, and GS12 solutions in reservoir brine (FW) and seawater (SW).

\subsection{Surface Tension Analysis}

The CMC was identified by using surface tension $(\gamma)$ and log surfactant molar concentration $(C)$ curves at $30{ }^{\circ} \mathrm{C}$ and $60{ }^{\circ} \mathrm{C}$. The maximum surface access at the air/solution interface $\left(\Gamma_{\max }\right)$ and the minimum area $\left(\mathrm{A}_{\min }\right)$ occupied by the surfactant was studied using Gibbs adsorption equations:

$$
\begin{aligned}
\Gamma_{\max } & =-\frac{1}{n R T}\left(\frac{\mathrm{d} \gamma}{\mathrm{d} \ln C}\right)_{\mathrm{T}} \\
\mathrm{A}_{\min } & =10^{18} / \mathrm{N}_{\mathrm{A}^{\Gamma} \max }
\end{aligned}
$$

Here $\mathrm{d} \gamma / \mathrm{d} \ln \mathrm{C}$ is the slope below CMC in surface tension plot, $\mathrm{R}$ is the gas constant, $\mathrm{C}$ represents the concentration of the surfactant, T represents temperature, $\mathrm{N}_{\mathrm{A}}$ is the Avogadro's number and $\mathrm{n}$ is three for the gemini amphiphile [43].

Figures 12-14 show the surface tension values of GS8, GS10, and GS12, respectively, at different temperatures and salinities. The derived surface properties are depicted in Table 6 . The decrease in surface tension was observed by enhancing the concentration of GS until CMC was achieved. Further addition of GS showed a negligible change in the surface tension beyond CMC. For all GSs with different spacer lengths, the CMC and surface tension at $\mathrm{CMC}\left(\gamma_{\mathrm{cmc}}\right)$ decreased upon enhancing salinity and temperature. At any concentration, the CMC and $\gamma_{\mathrm{cmc}}$ of the GSs were higher in DW as compared 
to the SW. Similarly, the $\mathrm{CMC}$ and $\gamma_{\mathrm{cmc}}$ were lower at high temperature $\left(60^{\circ} \mathrm{C}\right)$ as compared to low temperature $\left(30^{\circ} \mathrm{C}\right)$.

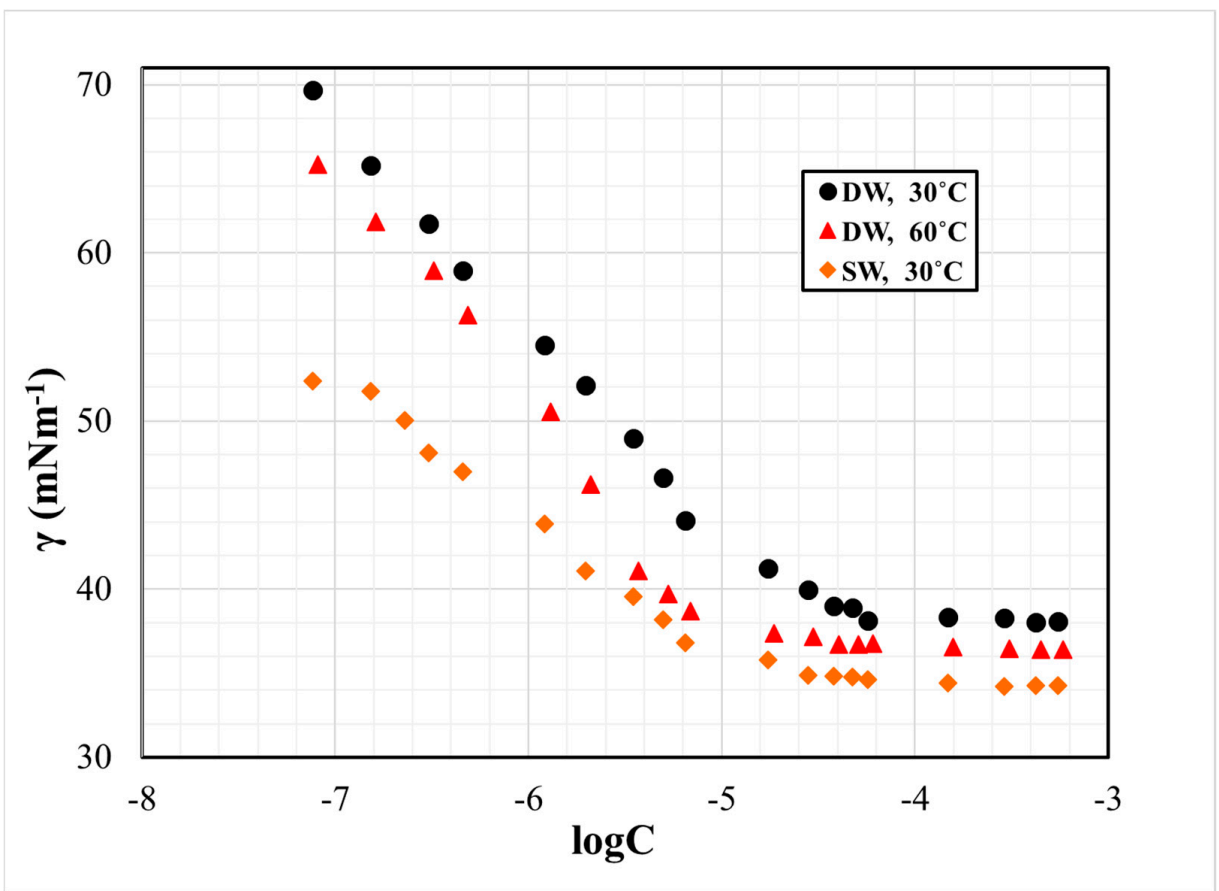

Figure 12. The surface tension of GS8 at different salinities and temperatures.

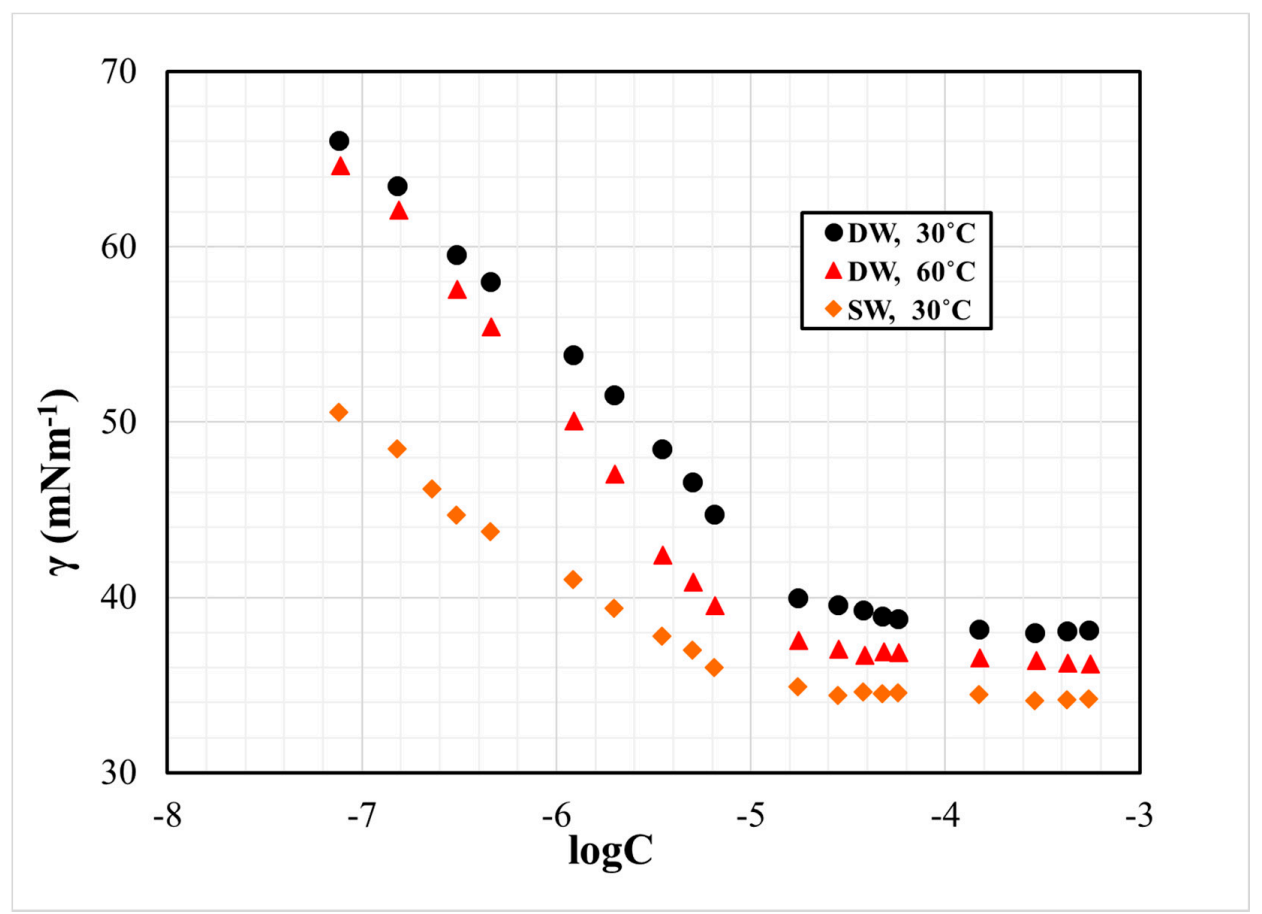

Figure 13. The surface tension of GS10 at different salinities and temperatures. 


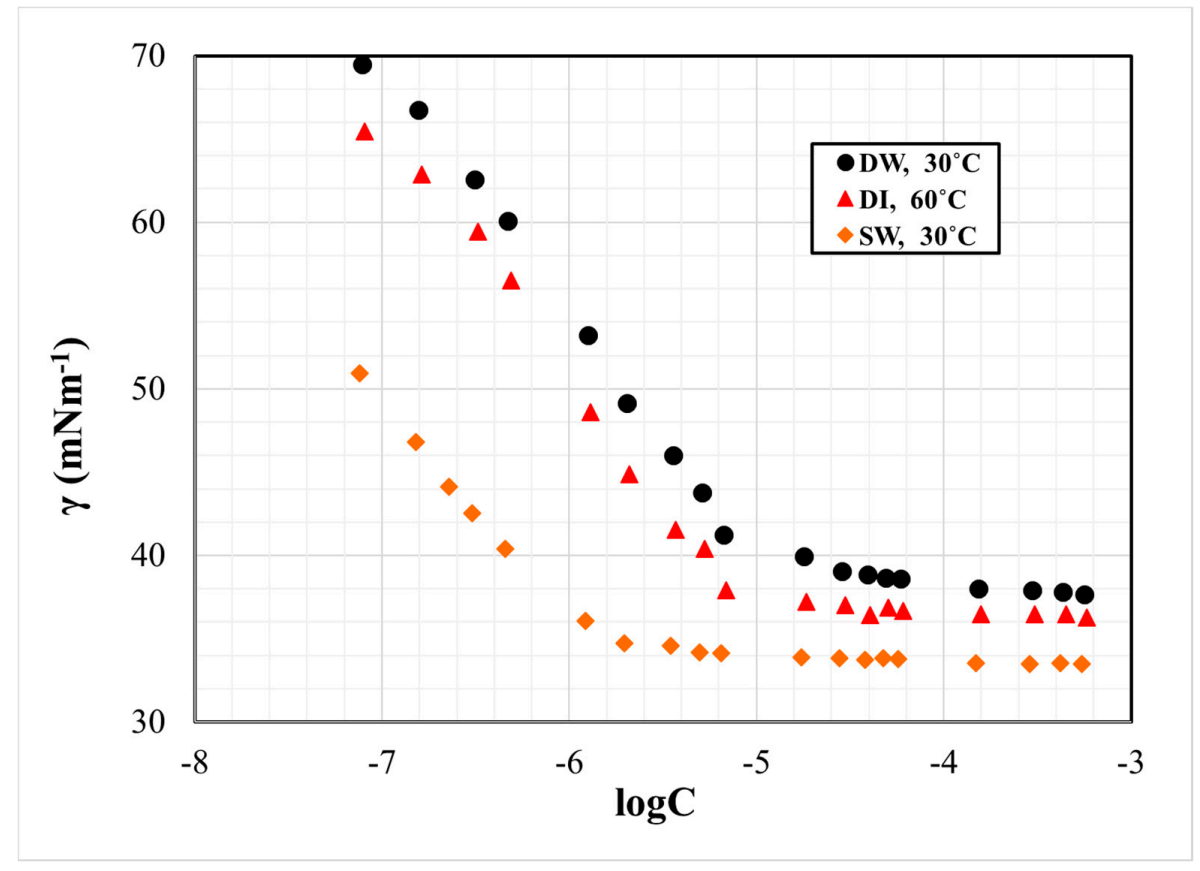

Figure 14. The surface tension of GS12 at different salinities and temperatures.

Table 6. Surface properties of GS8, GS10 and GS12 at various temperatures and salinities.

\begin{tabular}{|c|c|c|c|c|c|c|}
\hline Surfactant & Brine & $\mathrm{T}\left({ }^{\circ} \mathrm{C}\right)$ & $\mathrm{CMC}\left(\mathrm{mol} \mathrm{L}^{-1}\right)$ & $\gamma_{\mathrm{cmc}}\left(\mathrm{mN} \mathrm{m}^{-1}\right)$ & $\Gamma_{\max } \times 10^{7}\left(\mathrm{~mol} \mathrm{~m}^{-2}\right)$ & $A_{\min }\left(n m^{2}\right)$ \\
\hline GS8 & DW & 30 & $1.86 \times 10^{-5}$ & 40.31 & 7.23 & 2.33 \\
\hline GS8 & DW & 60 & $7.12 \times 10^{-6}$ & 37.71 & 6.63 & 2.50 \\
\hline GS8 & SW & 30 & $1.09 \times 10^{-5}$ & 34.29 & 5.94 & 2.79 \\
\hline GS10 & DW & 30 & $1.068 \times 10^{-5}$ & 39.70 & 7.35 & 2.25 \\
\hline GS10 & DW & 60 & $6.85 \times 10^{-6}$ & 37.39 & 6.53 & 2.48 \\
\hline GS10 & SW & 30 & $7.67 \times 10^{-6}$ & 34.70 & 5.78 & 2.75 \\
\hline GS12 & DW & 30 & $8.26 \times 10^{-6}$ & 39.55 & 8.84 & 1.89 \\
\hline GS12 & DW & 60 & $6.55 \times 10^{-6}$ & 37.38 & 8.36 & 1.99 \\
\hline GS12 & SW & 30 & $1.69 \times 10^{-6}$ & 33.93 & 7.85 & 2.11 \\
\hline
\end{tabular}

The surface tension values depend on the interaction of the molecules of GS at the water-micelle interface. Any factor (internal or external) that facilitate the presence of GS at the water-micelle interface will result in surface tension reduction [23]. Increasing the concentration of salts also increases the presence of the GS at the water-micelle interface by lowering the hydration of surfactant molecules. Increasing the concentration of salts also reduces the repulsion of GS molecule which results in more close packing at the water-micelle interface. Therefore, increasing the concentration of salts lowers the CMC and $\gamma_{\mathrm{cmc}}$ values. The synthesized GS8, GS10, and GS12 have similar alky tail, EO units, and ammonium headgroup. The only difference is the length of the spacer which is the only factor responsible for determining aggregation morphologies. The CMC of GSs at $30{ }^{\circ} \mathrm{C}$ and $60{ }^{\circ} \mathrm{C}$, as well as in DW and SW, was in the order of GS12 < GS10 < GS8 because the longer GS12 spacer makes it easier to be situated at the water-micelle interface and forms a more closely packed micelle structure [28]. GS12 showed the minimum CMC $\left(6.55 \times 10^{-6} \mathrm{~mol} / \mathrm{L}\right)$ in DW at $60{ }^{\circ} \mathrm{C}$ followed by GS10 and GS8. A similar trend was observed at both salinities and temperatures for GS8, GS10 and GS12 and these results are in agreement with the literature $[18,19]$. The surface access $\left(\Gamma_{\max }\right)$ decreased upon enhancing salinity and temperature but increased by increasing spacer length in the order GS12 > GS10 > GS8. A minimum area occupied by GS $\left(\mathrm{A}_{\min }\right)$ also influenced by the spacer length, salinity, and temperature. $A_{\text {min }}$ reduced upon increasing spacer length in the order of GS12 < GS10 < GS8 but increased by increasing salinity and temperature. In summary, all the synthesized GSs exhibited very low CMC in DW and SW. 


\section{Conclusions}

Environmentally friendly gemini surfactants are comparatively new materials for oilfield application. In this report, three quaternary ammonium gemini surfactants (GS8, GS10, GS12) with the same functionalities, except for the length of the spacer, were synthesized and characterized by FT-IR, ${ }^{13} \mathrm{C}$ NMR, ${ }^{1} \mathrm{H}$ NMR, and MALDI-TOF MS. The effect of flexible larger spacers (C8, C10, and $\mathrm{C} 12)$ on the thermal and surface properties was studied. According to TGA analysis, the GSs showed almost similar thermograms and exhibited higher decomposition temperature $\left(227^{\circ} \mathrm{C}\right)$ compared to existing oilfield temperature $\left(\geq 90^{\circ} \mathrm{C}\right)$. The GSs exhibited excellent solubility in normal and saline water and the aqueous solutions of GS8, GS10, GS12 stayed clear for up to three months at $90{ }^{\circ} \mathrm{C}$ without precipitation or phase separation. It was noticed that the increase in spacer length shifts the CMC and $\gamma_{\mathrm{cmc}}$ to lower values in the order of GS8 > GS10 > GS12. The larger spacer in GS12 stimulates micelle formation at the water-micelle interface and creates a more closely packed micelle structure which leads to a lower CMC. The effect of salinity and temperature on micellization was also investigated through surface tension measurements. A significant decrease in CMC and $\gamma_{\mathrm{cmc}}$ was observed in the presence of salts and at high temperature. The IFT, rheology, and foam analysis are proceeding in our laboratories.

Supplementary Materials: The following are available online at http://www.mdpi.com/1996-1073/12/9/1731/s1, Figure S1: ${ }^{1} \mathrm{H}$ NMR of quaternary ammonium gemini surfactants (GS8); Figure S2: ${ }^{13} \mathrm{C}$ NMR of quaternary ammonium gemini surfactants (GS8); Figure S3: FT-IR spectra of quaternary ammonium gemini surfactants (GS8); Figure S4: MALDI-TOF MS analysis of quaternary ammonium gemini surfactants (GS8); Figure S5: ${ }^{1} \mathrm{H}$ NMR of quaternary ammonium gemini surfactants (GS10); Figure S6: ${ }^{13} \mathrm{C}$ NMR of quaternary ammonium gemini surfactants (GS10); Figure S7: FT-IR spectra of quaternary ammonium gemini surfactants (GS10); Figure S8: MALDI-TOF MS analysis of quaternary ammonium gemini surfactants (GS10).

Author Contributions: Conceptualization, M.S.K. and S.M.S.H.; methodology, S.M.S.H. and M.M.; data curation, S.M.S.H. and M.M.; writing-original draft preparation, S.M.S.H. and M.S.K.; supervision, M.S.K.; project administration, M.S.K.

Funding: This research was funded by College of Petroleum Engineering \& Geoscience (CPG), King Fahd University of Petroleum \& Minerals, through a joint project with UT Austin under the grant number CPG-17-0124 and the APC was funded by College of Petroleum Engineering \& Geoscience.

Acknowledgments: The research was supported by the College of Petroleum Engineering \& Geoscience (CPG) at KFUPM through a collaborative project with The University of Texas at Austin.

Conflicts of Interest: The authors declare no conflict of interest.

\section{References}

1. Migahed, M.; EL-Rabiei, M.; Nady, H.; Zaki, E. Novel Gemini cationic surfactants as anti-corrosion for X-65 steel dissolution in oilfield produced water under sweet conditions: Combined experimental and computational investigations. J. Mol. Struct. 2018, 1159, 10-22. [CrossRef]

2. Mao, J.; Yang, X.; Chen, Y.; Zhang, Z.; Zhang, C.; Yang, B.; Zhao, J. Viscosity reduction mechanism in high temperature of a Gemini viscoelastic surfactant (VES) fracturing fluid and effect of counter-ion salt $(\mathrm{KCl})$ on its heat resistance. J. Pet. Sci. Eng. 2018, 164, 189-195. [CrossRef]

3. Nguele, R.; Sasaki, K.; Said-Al Salim, H.; Sugai, Y.; Widiatmojo, A.; Nakano, M. Microemulsion and phase behavior properties of (Dimeric ammonium surfactant salt-heavy crude oil-connate water) system. J. Unconv. Oil Gas Resour. 2016, 14, 62-71. [CrossRef]

4. Zhou, M.; Zhang, Z.; Xu, D.; Hou, L.; Zhao, W.; Nie, X.; Zhou, L.; Zhao, J. Synthesis of three gemini betaine surfactants and their surface active properties. J. Taiwan Inst. Chem. Eng. 2017, 74, 7-13. [CrossRef]

5. Wang, Y.; Jiang, Y.; Geng, T.; Ju, H.; Duan, S. Synthesis, surface/interfacial properties, and biological activity of amide-based Gemini cationic surfactants with hydroxyl in the spacer group. Colloids Surf. A Physicochem. Eng. Asp. 2019, 563, 1-10. [CrossRef]

6. Abo-Riya, M.; Tantawy, A.H.; El-Dougdoug, W. Synthesis and evaluation of novel cationic gemini surfactants based on Guava crude fat as petroleum-collecting and dispersing agents. J. Mol. Liq. 2016, 221, 642-650. [CrossRef] 
7. Mao, J.; Wang, D.; Yang, X.; Zhang, Z.; Yang, B.; Zhang, C. Adsorption of surfactant on stratum rocks: Exploration of low adsorption surfactants for reservoir stimulation. J. Taiwan Inst. Chem. Eng. 2019, 95, 424-431. [CrossRef]

8. Liu, S.; Liu, X.; Guo, Z.; Liu, Y.; Guo, J.; Zhang, S. Wettability modification and restraint of moisture re-adsorption of lignite using cationic gemini surfactant. Colloids Surf. A Physicochem. Eng. Asp. 2016, 508, 286-293. [CrossRef]

9. Pal, N.; Saxena, N.; Mandal, A. Studies on the physicochemical properties of synthesized tailor-made gemini surfactants for application in enhanced oil recovery. J. Mol. Liq. 2018, 258, 211-224. [CrossRef]

10. Olayiwola, S.O.; Dejam, M. A comprehensive review on interaction of nanoparticles with low salinity water and surfactant for enhanced oil recovery in sandstone and carbonate reservoirs. Fuel 2019, 241, 1045-1057. [CrossRef]

11. Kaczerewska, O.; Brycki, B.; Ribosa, I.; Comelles, F.; Garcia, M.T. Cationic gemini surfactants containing an O-substituted spacer and hydroxyethyl moiety in the polar heads: Self-assembly, biodegradability and aquatic toxicity. J. Ind. Eng. Chem. 2018, 59, 141-148. [CrossRef]

12. Lim, J.; Kang, E.K.; Lee, H.; Lee, B.M. Synthesis and interfacial properties of ethoxylated cationic surfactants derived from n-dodecyl glycidyl ether. J. Ind. Eng. Chem. 2015, 22, 75-82. [CrossRef]

13. Bhat, I.A.; Roy, B. Synthesis and biophysical analysis of a novel gemini surfactant with lysozyme: Industrial perspective. J. Ind. Eng. Chem. 2018, 63, 348-358. [CrossRef]

14. Akram, M.; Anwar, S.; Bhat, I.A. In vitro evaluation of the non-covalent interactions of hemoglobin with distinctively modified gemini surfactants: Effect of structural variation. Colloids Surf. A Physicochem. Eng. Asp. 2017, 527, 145-157. [CrossRef]

15. Zhou, L.; Jiang, X.; Li, Y.; Chen, Z.; Hu, X. Synthesis and properties of a novel class of gemini pyridinium surfactants. Langmuir 2007, 23, 11404-11408. [CrossRef]

16. Shakil Hussain, S.; Animashaun, M.A.; Kamal, M.S.; Ullah, N.; Hussein, I.A.; Sultan, A.S. Synthesis, characterization and surface properties of amidosulfobetaine surfactants bearing odd-number hydrophobic tail. J. Surfactants Deterg. 2016, 19, 413-420. [CrossRef]

17. Zana, R. Dimeric (gemini) surfactants: Effect of the spacer group on the association behavior in aqueous solution. J. Colloid Interface Sci. 2002, 248, 203-220. [CrossRef]

18. Bhadani, A.; Kataria, H.; Singh, S. Synthesis, characterization and comparative evaluation of phenoxy ring containing long chain gemini imidazolium and pyridinium amphiphiles. J. Colloid Interface Sci. 2011, 361, 33-41. [CrossRef]

19. Li, F.; Rosen, M. Adsorption of gemini and conventional cationic surfactants onto montmorillonite and the removal of some pollutants by the clay. J. Colloid Interface Sci. 2000, 224, 265-271. [CrossRef]

20. Zhang, T.; Cao, X.; Wang, X.; Song, C. Synthesis, surface activity and thermodynamic properties of cationic gemini surfactants with diester and rigid spacers. J. Mol. Liq. 2017, 230, 505-510. [CrossRef]

21. Ao, M.; Huang, P.; Xu, G.; Yang, X.; Wang, Y. Aggregation and thermodynamic properties of ionic liquid-type gemini imidazolium surfactants with different spacer length. Colloid Polym. Sci. 2009, 287, $395-402$. [CrossRef]

22. Taleb, K.; Pillin, I.; Grohens, Y.; Saidi-Besbes, S. Gemini surfactant modified clays: Effect of surfactant loading and spacer length. Appl. Clay Sci. 2018, 161, 48-56. [CrossRef]

23. Wang, X.; Wang, J.; Wang, Y.; Yan, H.; Li, P.; Thomas, R.K. Effect of the nature of the spacer on the aggregation properties of gemini surfactants in an aqueous solution. Langmuir 2004, 20, 53-56. [CrossRef] [PubMed]

24. Chorro, M.; Chorro, C.; Dolladille, O.; Partyka, S.; Zana, R. Adsorption mechanism of conventional and dimeric cationic surfactants on silica surface: Effect of the state of the surface. J. Colloid Interface Sci. 1999, 210, 134-143. [CrossRef] [PubMed]

25. Pal, N.; Kumar, N.; Verma, A.; Ojha, K.; Mandal, A. Performance evaluation of novel sunflower oil-based gemini surfactant (s) with different spacer lengths: Application in enhanced oil recovery. Energy Fuels 2018, 32, 11344-11361. [CrossRef]

26. Pal, N.; Saxena, N.; Mandal, A. Characterization of alkali-surfactant-polymer slugs using synthesized gemini surfactant for potential application in enhanced oil recovery. J. Pet. Sci. Eng. 2018, 168, 283-300. [CrossRef]

27. Panda, M.; Fatma, N. Enhanced aqueous solubility of polycyclic aromatic hydrocarbons by green diester-linked cationic gemini surfactants and their binary solutions. J. Mol. Struct. 2016, 1115, 109-116. [CrossRef] 
28. Hussain, S.S.; Kamal, M.S. Effect of large spacer on surface activity, thermal, and rheological properties of novel amido-amine cationic gemini surfactants. J. Mol. Liq. 2017, 242, 1131-1137. [CrossRef]

29. Chu, Z.; Feng, Y. A facile route towards the preparation of ultra-long-chain amidosulfobetaine surfactants. Synlett 2009, 2009, 2655-2658.

30. Zana, R.; Benrraou, M.; Rueff, R. Alkanediyl- $\alpha, \omega$-bis (dimethylalkylammonium bromide) surfactants. 1. Effect of the spacer chain length on the critical micelle concentration and micelle ionization degree. Langmuir 1991, 7, 1072-1075. [CrossRef]

31. Atta, A.M.; Al-Lohedan, H.A.; Abdullah, M.M.; ElSaeed, S.M. Application of new amphiphilic ionic liquid based on ethoxylated octadecylammonium tosylate as demulsifier and petroleum crude oil spill dispersant. J. Ind. Eng. Chem. 2016, 33, 122-130. [CrossRef]

32. Hussain, S.S.; Kamal, M.S.; El Ali, B.; Sultan, A.S. Synthesis and evaluation of novel Amido-amine cationic Gemini surfactants containing flexible and rigid spacers. J. Surfactants Deterg. 2017, 20, 777-788. [CrossRef]

33. Huc, I.; Oda, R. Gemini surfactants: Studying micellisation by ${ }^{1} \mathrm{H}$ and ${ }^{19} \mathrm{~F}$ NMR spectroscopy. Chem. Commun. 1999, 2025-2026. [CrossRef]

34. Jiang, Y.; Chen, H.; Cui, X.-H.; Mao, S.-Z.; Liu, M.-L.; Luo, P.-Y.; Du, Y.-R. ${ }^{1}$ H NMR study on pre-micellization of quaternary ammonium gemini surfactants. Langmuir 2008, 24, 3118-3121. [CrossRef] [PubMed]

35. Guerrero-Martínez, A.; González-Gaitano, G.; Viñas, M.H.; Tardajos, G. Inclusion complexes between $\beta$-cyclodextrin and a gemini surfactant in aqueous solution: An NMR study. J. Phys. Chem. B 2006, 110, 13819-13828. [CrossRef]

36. Huang, X.; Han, Y.; Wang, Y.; Cao, M.; Wang, Y. Aggregation properties of cationic gemini surfactants with dihydroxyethylamino headgroups in aqueous solution. Colloids Surf. A Physicochem. Eng. Asp. 2008, 325, 26-32. [CrossRef]

37. Al-Sabagh, A.; Azzam, E.; Mahmoud, S.; Saleh, N. Synthesis of ethoxylated alkyl sulfosuccinate surfactants and the investigation of mixed solutions. J. Surfactants Deterg. 2007, 10, 3-8. [CrossRef]

38. Ghumare, A.K.; Pawar, B.V.; Bhagwat, S.S. Synthesis and antibacterial activity of novel amido-amine-based cationic gemini surfactants. J. Surfactants Deterg. 2013, 16, 85-93. [CrossRef]

39. Dong, S.j.; Li, Y.l.; Song, Y.b.; Zhi, L.f. Synthesis, Characterization and Performance of Unsaturated Long-Chain Carboxybetaine and Hydroxy Sulfobetaine. J. Surfactants Deterg. 2013, 16, 523-529. [CrossRef]

40. Azad, M.S.; Sultan, A.S.; Nuaim, S.A.; Mahmoud, M.; Hussein, I.W. Could VES be a part of Hybrid option to recover Heavy oil in Complex Heavy oil Reservoirs. In Proceedings of the SPE Heavy Oil Conference, Calgary, AB, Canada, 10-12 June 2014.

41. Mohajeri, M.; Hemmati, M.; Shekarabi, A.S. An experimental study on using a nanosurfactant in an EOR process of heavy oil in a fractured micromodel. J. Pet. Sci. Eng. 2015, 126, 162-173. [CrossRef]

42. Sagir, M.; Tan, I.M.; Mushtaq, M.; Ismail, L.; Nadeem, M.; Azam, M.R.; Hashmet, M.R. Novel surfactant for the reduction of CO2/brine interfacial tension. J. Dispers. Sci. Technol. 2014, 35, 463-470. [CrossRef]

43. Nessim, M.I.; Osman, M.M.; Ismail, D.A. Surface-active properties of new cationic gemini surfactants with cyclic spacer. J. Dispers. Sci. Technol. 2018, 39, 1047-1055. [CrossRef]

(C) 2019 by the authors. Licensee MDPI, Basel, Switzerland. This article is an open access article distributed under the terms and conditions of the Creative Commons Attribution (CC BY) license (http://creativecommons.org/licenses/by/4.0/). 